\title{
Improving Korea's Societal Security by Preparing for Unforeseen Disasters: Focused on the Horizontal Collaboration Approach
}

\author{
Younhee Kim ${ }^{1}$, Hakkyong $\mathrm{Kim}^{2 *}$ \\ ${ }^{1}$ Disaster Management Training Division, \\ National Civil Defense and Disaster Management Training Institute \\ Tajosan-Gill, Chunan-Si, Chungchungnam-Do, Korea \\ Ykim5@korea.kr \\ ${ }^{2}$ Dept. of Convergence Security, Sungshin Women's University \\ 2, Bomun-Ro 34Da-Gil, Seongbuk-Gu, Seoul, Korea \\ *pocol@sungshin.ac.kr
}

\begin{abstract}
Recently, unforeseen disasters have occurred, such as the Fukushima nuclear disaster in Japan and the tragic Sewol ferry incident in Korea. These unforeseen disasters challenged national emergency management capacities in many ways. We are living in a very complex and ever-changing society, and so, improving social security against these disasters is critically important. This paper discusses changes to emergency management to bring contemporary response standards into the aging system. Particular focus is on Korea's emergency management systems and preparing for the unforeseen events in Korea. Finally, this paper suggests the horizontal collaboration approach at the local level, and further suggests three practical ways of horizontal collaboration to promote effective and efficient response against unforeseen disasters in Korea.
\end{abstract}

Keywords: Societal Security, Disaster Preparedness, Plan and Procedure, Response Exercise

\section{Introduction}

Risk is everywhere, both natural and as a by-product of human activity. Beck argues that we live in a 'Risk Society', where uncertainty, complexity, and the multiplicity of new technologies are increasing at an unprecedented rate, and it is impossible to foresee all the hazards and potentially deadly consequences of all of our "advancements" in an accurately fashion [1]. Society is best served by calculating a measure of these unforeseeable disaster risks as a critical organizing principle in modern society.

By definition, emergencies hit suddenly and evolve rapidly, rarely emerging and developing in a manner anticipated by emergency management systems. Some examples of recent, high-profile, unsuccessful national emergency management responses to mega-disasters include FEMA's failed response to Hurricane Katrina in 2005 and Japan's to its 2011 tsunami. In those events, the total failure of the existing emergency response systems has been well documented. These help to illustrate the need for the emergency management community to begin to expand the scope of contingency plans, particularly in order to include total failure scenarios of necessary components such as telecommunication, electricity, and supply chains.

This paper discusses some possible changes of emergency management to make it more fluid in its responsiveness to disaster. In particular, this paper will address Korea's emergency management systems and how they can be substantially

* Hakkyong Kim is the corresponding author. 
improved. Finally, this research suggests a horizontal approach for promoting emergency management capacities and for building better societal security.

\section{Perspective Changes of Emergency Management}

Emergency management is defined as the discipline and profession of applying science, technology, planning and management to deal with extreme events that can injure or kill a great number of people, do extensive property damage, and disrupt community life [2]. Although there are some variations, this definition is widely accepted.

The widely known steps of crisis or disaster management are: 1) identifying vulnerability, 2) calculating risks by multiplying the frequencies and impacts, 3) making a contingency plan based on the highly-ranked risks, and 4) finally exercising and testing the plan; these are regarded as the key steps of traditional crisis management. Many organizations and even national governments follow these steps and guidelines for their emergency management systems. For example, the United States of America develops the national emergency management documents such as the Homeland Security Exercise and Evaluation Program and the National Response Framework, which also follow the typical strategies of crisis, emergency and risk management.

Borodzicz argues that new types of disasters and crises are emerging, caused by changes in the way we live [3]. Natural phenomena such as earthquakes, floods, wind, drought and tsunami are not at all new, but higher levels of population density, travel and mechanized forms of food production and a reliance on technology to facilitate modern life styles, mean that when these events do occur, they will have a potential to cause serious impact to greater numbers of people in alarmingly new ways. He also argues that we have witnessed a black swan syndrome, system failure, human irrationality, and rapid population growth. With modern iterations of these phenomena, traditional emergency management approaches have been challenged in many ways and finally found to be inadequate. Most of the challenges are caused by non-standard events which demonstrate that risk in our era cannot be foreseen, and hence, it is hard to manage or respond in a competent way. In the face of these modern events, emergency managers encounter extraordinary challenges, both in number and severity, and as a result, must prepare for and respond to natural hazards and disasters through intergovernmental collaboration [13].

To be equal to the challenges presented by mega-disasters, current (traditional) crisis and risk management strategies need to be changed. The traditional strategies of the crisis and emergency management won't work for the non-standard crisis situations. Training emergency management personal, educating people and testing contingency plans are the key success factors meeting crisis situations head-on. However, these types of traditional methods are no longer working properly in riskaverse society and, rather, results in magnification of risk to societal security rather than shoring it up.

Perspective changes on crisis and risk management have great impacts on policy makers. Indeed, many countries are facing the challenges of preparing for unforeseen crises and emergencies as well as other unknown risks. Responding to unforeseen events and promoting a societal security are the main focuses of emergency management, and policy makers should make a paradigm shift in their thinking regarding crisis and emergency management. 


\section{Current Practice of Emergency Management in Korea}

Traditionally, Korea is exposed to such natural disasters as typhoons, floods, heat-waves and drought. These have been the drivers of various emergency management programs in Korea, enabling them to prepare for, mitigate, respond to, and recover from these hazards. In order to manage the various hazards and risks, individual laws and initiatives including the Flood Management Act, the Natural Hazard Management Act, the Small Stream Management Act, and the Disaster Relief Act were enacted, and the relevant ministries and agencies took diffused responsibilities of dealing with each hazard and risk. Managing each hazard and risk by an individually assigned government entity was the practice of emergency management in Korea until typhoon Rusa in 2002 and the subway explosion in Daegu in 2003. These extreme events in the early 2000 have caused Korea to finally realize the need for a comprehensive emergency management approach.

Hence, the Disaster and Safety Basic Law was enacted in 2004, and the National Emergency Management Agency (NEMA) was established to enhance and integrate the existing emergency management systems in Korea. Disaster types are categorized into three sub-types: natural, human-induced, and social disasters. Korea became a country that managed hazards and emergencies by a disaster type (category). Korea then prepared its national emergency management system, standardized and streamlined official disaster response contingencies with such structured documents as National Crisis Manuals by disaster types.

Currently, thirty disaster types are defined in the Presidential Directive on the National Crisis Management Guide. Consequently, such a system produced over five thousand crisis management manuals in Korea because ministries and agencies are responsible for making each crisis management manual in each disaster type. Most of the current emergency management documents emphasize the roles and responsibilities of the authoring organizations alone. However, this alarming multiplicity of published, specialized response plans has rather created Korea's socalled "reporting culture" among emergency management organizations within the government, making achieving the inter-organizational collaboration nearly impossible, and certainly impractical.

Korea now faces big challenges to its national emergency management system. The Sewol sinking exposed the weakness and institutional paralysis of the existing system .Other events that stymied the system were also the landslide of Woomyun Mountain, and the Mauna resort collapse in Korea. Korea's emergency management "report culture" is to blame for inadequate and incompetent responses to these insofar as it does not embrace the concept of collaboration and coordination among emergency management stakeholders. Current practices of Korean emergency management needs rapid changes to equip it to properly deal with the non-standard events in the best interests of society.

Philips argues that adaptive behaviors are needed to enhance or improve emergency response capacity [4]. In order to do that, different types of response exercises need to be given to not only emergency mangers but also the general public. However, the current practices of Korean disaster exercises are still restricted to familiarizing people with necessary skills and locations, mechanistically, in a rote fashion - namely, by sticking to a pre-determined scenario script through repeated rehearsals [5,9].

In other words, most Korean disaster exercises or crisis simulations are very controlled, with no allowance for digression. These apply a very detailed scenario script for the purpose of producing an error-free exercise. Moreover, the exercise scenario scripts are distributed to exercise players in advance so that they can 
become fully aware of what will unfold and what they are expected to do in simulations.

A more realistic test of responsiveness, however, would keep secret the precise details of the incident such that the exercise could be as realistic as possible for the exercise players taking part. Otherwise, learning may well be constrained because the participants are already briefed about the expected outcomes $[4,5,6]$. In this sense, it is doubtful whether, or how, the current practices of Korean exercises Scripted Exercises actually enable people to deal with unexpected situations which are not part of the exercise scenario scripts, although nearly all of the crisis disaster exercises in Korea are evaluated as "Successful" in the media.

These practices can produce 'open systems paradox' [7,18]. A crisis is an 'open system', where there are numerous equally but different possible scenarios by which a crisis can develop into a disaster. In contrast, a pre-set scenario script is a closed system, where every move and action is prescribed and fixed, without allowing any flexibility. Accordingly, in closed system exercises 'worst case' scenarios are seldom considered, although a valuable exercise of flexibility in responses is vital to preparing for a crisis $[4,5,8]$. Hence, the current scripted exercises in Korea with a very detailed, pre-determined scenario script cannot handle possible variables, such as traffic congestion or adverse weather which might influence the late arrival of emergency services, nor can they take into account human variables such as mistakes, errors, and conflicting viewpoints about disaster response [9].

To sum up, it is not possible to foresee every single worst case scenario, stipulate its response in a plan, and test it through exercises. Too much dependence on predetermined rules and procedures might rather produce disaster exercise paradoxes. For this reason, crisis or disaster responses need to be improvised to some extent, based on circumstances, time constraints, and limiting resources available, case by case $[4,5]$.

\section{Promoting Horizontal Collaboration among Emergency Management Stakeholders at the Local Level}

In complex social settings, responsibilities of emergency management fall on not only the public sectors but also the private sectors. According to Sylves, emergency management is, by its very nature, inter-governmental and inter-communal [2]. Disaster responses require the cooperation and coordination among different levels of governments and other organizations - including volunteer organizations and private sectors. Failure of prompt responses in the local communities makes the losses and damages to those communities and the nation bigger and more severe. Collaboration should be stressed among multi-sectors at the local level.

The concept of collaboration is widely discussed in the many academic disciplines including public administrations, policy studies, and emergency management studies. Collaboration has become one of the most important research topics in emergency management. Since local governments are designed as the first line to respond to emergencies, collaboration is generally viewed as a useful strategy for local governments to effectively manage cross-sector resources for handling both natural and man-made disasters [10]. Particularly in the emergency management context, two important concepts of collaborations exist: vertical and horizontal collaborations.

In the case of the vertical collaboration in the United States of America, the federal-state-local structures are the basic framework in the American politics, law enforcement, tax and finance, and policy implementation [10]. This structure has been applied to the emergency management system in the form of a tiered response system, which has been documented in the National Response Framework. 
The vertical collaboration system in the Korean emergency management is a central - local structure, which is well described in the various emergency management documents including the National Safety Plans and the National Crisis Management Manuals. Korea is a country where vertical collaboration is enforced in order to create the necessary coordination between local governments. For this reason, the central government and vertical collaboration are also strongly infused into the emergency management system. The vertical collaboration structure can be easily recognized in various emergency management documents in Korea.

However, local communities are usually where emergencies and disasters take place. Recognizing this, many countries impose the responsibilities of initial emergency response on the local governments. For instance, in the United States the tiered response principle is introduced in the National Response Framework, where it is clearly stated that local communities are responsible for the initial responses for emergencies and disasters. The first burden for local communities, then, is to engage in pre-disaster activities including preparations and planning.

Many researchers point out that one of the weakest links of the current emergency system in Korea is the absence of the horizontal collaboration. In horizontal collaboration, local governments frequently cooperate with public agencies, other local governments, business industries, and non-profit organizations either to develop mitigation and preparedness activities, or to respond to and recover from the disaster [10]. However, these types of collaborations in the field of emergency management are hard to find, particularly at the local level in Korea. In this context, this paper suggests the horizontal collaboration approach in Korea, for the local governments to deliver initial, effective and prompt response to emergency situations.

Characteristic responses to disasters create intergovernmental fragmentation issues. Due to the fragmentation of disaster responsibilities, designing and developing an effective and efficient disaster management system at the national level is critical but hard to implement. Collaboration and cooperation among emergency stakeholders are getting more important, and indeed should be strongly emphasized.

Surprisingly, horizontal collaboration is only recently recognized in the emergency management field in Korea. The horizontal collaboration approach was suggested initially in the public management field where the concept of the collaborative public management was emphasized in the 21 century [10]. The concept of collaboration, especially inter-organizational collaboration is defined as a process in which organizations exchange information, alter activities, share resources, and enhance each other's capacity for mutual benefits and a common purpose by sharing risks, responsibilities and rewards [11]. Agranoff and McGuire argue that collaboration is a process in which more than one organization or individual works together to solve complicated problems [12]. Organizations and individuals come to share mutual goals, trust and benefits, and establish a long-term interdependent relationship.

As demonstrated by a number of recent disasters in Korea, collaboration across the governmental boundaries is imperative, both before and after disasters. In many ways, emergency management is recognized as an ideal context where the general forces of intergovernmental collaboration can be tested. For this reason, emergency management has evolved over time from a predominantly hierarchical command and control management model to a collaborative one [13].

Korea is a country where vertical collaborations are firmly in place. Now horizontal collaboration is urgently needed for a more flexible emergency management system, especially for the response phase. In order to deliver effective responses to emergencies at the local level, local governments must operate two 
types of horizontal collaborations: inter-government collaboration and inter-sectoral collaboration.

The inter-governmental collaboration is often studied as one of the research topics in the public management area. Since emergency management is a part of public management, the collaboration among multiple agencies has been a constant study topic. In this paper, inter-government collaboration refers to the collaborations of the public entities at the local level, which includes fire, police, ambulance, emergency medicine, and emergency management offices at the local level. In other words, collaboration between first responders' organizations and local governments is needed for improving seamless emergency response and recovery.

The inter-sectoral collaboration describes the interactions across public and private sectors or public and non-profit sectors within a policy network through the form of contracts and formal agreements [14] or sharing resources on a case by case basis. In order to promote horizontal collaboration at the local level, this paper strongly suggests three practical implementation steps listed below.

First, consensus building on horizontal collaborations among local stakeholders regarding roles and responsibilities in emergency responses needs to be promoted. Currently, the practice of emergency management in Korea, particularly, the level of collaboration often is driven by the personal qualities of leaders or commanders of agencies. So, this paper suggests that not only leaders but also emergency managers in local governments should be key focal points for consensus building for horizontal collaborations.

Horizontal collaboration is perfunctorily emphasized in the Korean emergency management surroundings, due to the strong vertical collaboration practices, and because of this, promoting horizontal collaboration and consensus building on horizontal collaborating among the local stakeholders is urgently needed. To do so, face to face meetings, seminars, and workshops among different organizations are strongly recommended. Statistics show that only a few local governments conduct the workshops and meetings among the diverse emergency management entities at the local level [15], and these practices need to be changed promptly.

Second, reflecting the concept of horizontal collaborations in existing emergency management is much needed. This existing emergency management system refers to the National Safety Management Plan, the National Crisis Response Manuals, and the relevant laws and regulations in Korea. Local governments need to involve private companies and non-profit organizations in the local planning process or sign mutual aid agreements with other local governments in adjacent communities in order to effectively respond to emergencies [10]. Put differently, horizontal collaboration needs to be included in disaster exercises planning documents. Currently, local governments are simply practicing inter-sectoral 'planning', and these practices have been an obstacle for effective and prompt emergency responses.

Further, the policy frame on horizontal collaboration, such as the National Incident Management System (NIMS) in the United States of America, needs to be established in the national emergency management system in Korea. According to FEMA, the NIMS is a national standard that "provides a systematic, proactive approach to guide departments and agencies at all levels of government, nongovernmental organizations, and the private sector to work seamlessly to prevent, protect against, respond to, recover from, and mitigate the effects of incidents, regardless of cause, size, location, or complexity, in order to reduce the loss of life and property and harm to the environment." [19]. Chang argues that the adoption of NIMS is positively associated with a high level of vertical collaboration and horizontal collaboration [10]. Since the organizational characteristics and 
institutional structures make collaboration complicated, the framework on horizontal collaboration such as NIMS needs to be established in Korea.

Finally, exercises and drills especially focused on exchanging the response resources at the local level also need to be implemented. In the horizontal approach, a local government can be not only a resource-seeker but also a resource-provider in the collaboration [10]. Currently, the inter-sectoral practices of exchanging response resources at the local level are very weak in Korea. Resources refer to human, information, physical equipment, as well as finance. Although there are common understandings of the need for sharing resources at the local level, the collaborative drills and exercises on exchange of resources are rarely conducted in Korea. Disaster exercises in Korea, such as the Safe Korea Exercise (SKX) and crisis manual drills, are heavily focused on vertical collaborations only. As a result, exchanging resources within collaboration drills and exercises need to be addressed in the current exercise schedules and planning processes.

Agranoff and McGuire argue that vertical collaborations can happen when local government seeks grant or program-oriented information or assistance from the state and federal government [12]. Unlike the vertical collaborations, horizontal collaborations are based on mutual understanding, based on a willingness to cooperate with one another. In Korea, the mutual aid agreements are usually made among the similar sectors, such as the fire stations and nearby police stations. However, in the field of emergency management, mutual aids among local governments are rare, and so the drills and exercises of resource exchange within the regional level are difficult to execute. Therefore, policy and regulations on resource exchange practices need to be established; furthermore, practical horizontal collaborations need to be conducted in exercises as well. In fact, exercises can be a proper way to improve adaptive behaviors towards emergencies, and this should an ultimate goal at the local level in the horizontal perspective.

O'Leary argues that emergency managers need to operate in both horizontal and vertical collaborations in all essential functions of emergency management [15]. Current emergency management in Korea urgently needs to improve horizontal collaborations in order to promote effective responses to the emergencies. Here, the horizontal approach is considered a valuable tool to significantly improve collaboration and cooperation, as local governments are responsible for first responses in emergencies and extreme events.

\section{Conclusion}

It is inevitable for emergency management leaders to encounter numerous challenges through various unforeseen and non-standards events. A new approach to understanding both the limitations of risk management and the opportunities, available to improve and enhance crisis response and resilience in organizations and social structures, is urgently required [3]. Now, the real question to answer is how we can prepare the inevitable unpredictable and unanticipatable events that defy standard preparation in the future.

Since Korea experienced tragic disasters in the past with less than acceptable emergency management response, now it is high time to prepare in more responsive ways for unforeseen events. The horizontal approach is suggested as an alternative to promote cooperation and collaboration among various emergency management stakeholders in Korea [17].

This research argues that the horizontal approach is the key success factor for better cooperation and collaborations for emergencies and unforeseen events. Regional and local levels of horizontal collaboration will help to promote the rapid and effective response for non-standard events. Three practical suggestions are 
presented in this paper, and these can be applied to inter-governmental as well as inter-sectoral collaborations.

Vertical and horizontal collaboration in local emergency management is a relatively emergent phenomenon, and one that is increasing in scope and importance. At the same time, a great deal of variation in the incidence of collaboration exists in many policy areas. Collaboration contemplates that disasters often exceed a single jurisdiction's or entity's abilities or resources, and almost never neatly contain themselves within a single city's, county's, or even state's boundaries. Therefore, intergovernmental and inter-sectoral collaboration is essential [13].

Therefore, collaboration at the local level is directly linked to citizens' safety and lives; this can be treated as an urgent public administrative goal. The horizontal approach can be applied to the regional and the local level in order to enhance the capacities of emergency management by conducting disaster exercises involving various public and private organizations. Implementing horizontal cooperation mechanisms in emergency management eventually can contribute to improving adaptive behaviors which are the greater portion of successful preparedness steps to manage the non-standards or unforeseen events.

This paper does not provide a comprehensive review of the application of the suggested horizontal approach at the local level. Further research needs to be conducted in order to review the impact of horizontal approaches for effective emergency management systems [17]. One of the future studies could be devoted to utilizing the three suggested practical ways of implementing horizontal collaboration stated herein, and reviewing their impact at the local level.

\section{Acknowledgements}

This paper is a revised and expanded version of a paper entitled "Improving Societal Security by Preparing (for) Non-Standard Events: Perspective on Korea's Crisis and Emergency Management" presented at the third workshop on Security, Reliability and Safety 2015, Jeju, Korea, December 14-16.

\section{References}

[1] U. Beck, Risk Society: Toward a New Modernity, Sage Publications, London (1992)

[2] R. Syleves, Disaster Policy \& Politics: emergency management and homeland security, CQ press, USA (2008)

[3] E. P. Borodzicz, Risky Business: Crisis Simulations Examined in the Context of the Safety People, Unpublished PhD Thesis, Birbeck College, University of London (1997)

[4] B. Phillips, D. Neal, and G. Webb, Introduction to Emergency Management, CRC Press, USA (2011)

[5] H. Kim, 'Improving simulation exercises in Korea for disaster preparedness', Disaster Prevention and Management (2013), vol.22, no.1, pp.38-47.

[6] V. S. Freimuth, K. M. Hilyard, J. K. Barge, and L. A. Sokler, 'Action, Not talk: A Simulation of Risk Communication during the First Hours of a Pandemic', Health Promotion Practice (2008), Vol.9, No.4, pp.35S-44S.

[7] B. Toft, Limits to the mathematical modeling of disasters, In Hood, C. and Jones, D., Accident and Design: Contemporary Debates in Risk Management, UCL press, London (1996), pp.99-110.

[8] M. Punch and G. Markham, 'Policing Disasters: the British Experience', International Journal of Police Science and Management (2000), Vol.3, No.1, pp.40-54.

[9] H. Kim and J. Lee, 'A Critical Review on Current Simulation Methodology', International Journal of Contents, (2011), Vol.7, No.1, pp.58-64.

[10] K. Chang, Understanding Cross-Sector Collaboration in Emergency Management: The Dynamics of Vertical and Horizontal Networks, Unpublished PhD thesis, the Florida State University, USA (2012)

[11] A. Parakash and S. G. Deshmukh, 'Horizontal Collaboration in Flexible Supply Chains: A Simulation Study', Journal of Studies on Manufacturing (2010), vol.1, no.1, pp.54-58.

[12] R. Agranoff and M. McGuire, 'Big Questions in Public Network Management Research', Journal of Public Administration Research and Theory (2001), vol.11, no.3, pp.295-326. 
[13] M. McGuire and C. Silvia, 'The Effect of Problem Severity, Managerial and Organizational Capacity, and Agency Structure on Intergovernmental, Collaboration: Evidence from Local Emergency Management', Public Administration Review (2010), vol.70, no.2, pp.279-288.

[14] B. Gazley, Intersectoral Collaboration and the Motivation to Collaborate toward an Integrated Theory In Big Ideas in Collaborative Public Management, Edited L. Bingham and R. O'Leary, M. E. Sharpe, New York (2008), pp.36-54.

[15] R. O'Leary and L.B. Bingham, The Collaborative Public Manager: New Ideas for the Twenty-first Century, Georgetown University Press, USA (2014)

[16] Y. Kim, and J. Park, A Study on Improving Disaster Management Training \& Exercise by Assessing Disaster Management Capacity in Local Governments, National Disaster Management Institute, Seoul (2013)

[17] Y. Kim and H. Kim, 'Improving Societal Security by Preparing Non-Standards Events: Perspective on Korea's Crisis and Emergency Management', Advanced Science and Technology (2015), vol.117, pp.101-105.

[18] H. Kim, 'Learning from UK disaster exercises: policy implications for effective emergency preparedness', Disasters, vol.38, no.4, pp.846-857.

[19] Department of Homeland Security, https://training.fema.gov/nims/
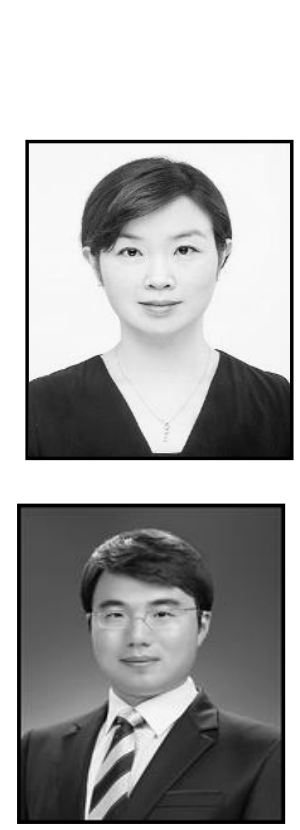

\section{Authors}

Younhee Kim, She is currently a Professor at the National Civil Defense and Disaster Management Training Institute, Ministry of Public Safety and Security in Korea. She received her D.Sc. in Crisis, Emergency and Risk management from George Washington University in the United States of America. Her research interests include national emergency management policy, disaster vulnerable people, and the information technology in emergency management.

Hakkyong Kim (Corresponding Author), $\mathrm{He}$ is currently a Professor at the Department of Convergence Security, Sungshin Women's University in Seoul. He graduated from the Korean National Police University in 1999. He earned his MSc degree in Risk, Crisis and Disaster Management from the University of Leicester, UK. He has completed his $\mathrm{PhD}$ research on a cross-cultural comparison of disaster exercises in Korea and the UK at the University of Portsmouth, UK. 
International Journal of Security and Its Applications

Vol. 10, No. 3 (2016) 